\title{
Prevalence and patterns of chronic disease multimorbidity and associated determinants in Canada
}

\author{
K. C. Roberts, MSc; D. P. Rao, MSc; T. L. Bennett, MSc; L. Loukine, MSc; G. C. Jayaraman, PhD
}

This article has been peer reviewed.

Tweet this article

\section{Abstract}

Introduction: Multimorbidity is increasingly recognized as a key issue in the prevention and management of chronic diseases. We examined the prevalence and correlates of chronic disease multimorbidity in the general adult Canadian population in relation to age and other key determinants.

Methods: We extracted data from the Canadian Community Health Survey 2011/12 on 105416 Canadians adults. We analysed the data according to the number of multimorbidities (defined as $2+$ or $3+$ diseases from a list of 9 ) and examined the determinants of multimorbidity using regression analyses.

Results: Our findings show that $12.9 \%$ of Canadians report $2+$ chronic diseases and $3.9 \%$ report $3+$ chronic diseases. Those reporting 3 or more chronic diseases were more likely to be female, older, living in the lowest income quintile and to have not completed high school. In the overall population, social deprivation is associated with a 3.7 odds of multimorbidity, but when examined across age groups, the odds of multimorbidity were notably higher in middle age, 7.5 for those aged 35 to 49 years and 5.4 for those aged 50 to 64 years.

Discussion: As the proportion of Canadians living with multiple chronic diseases increases, we need to assess chronic disease from a holistic perspective that captures multimorbidity and upstream factors, to facilitate broader and more context-appropriate associations with healthy living, quality of life, health care costs and mortality. Special consideration should be given to the role that social deprivation plays in the development of multimorbidity. Canadians living in the lowest socioeconomic group are not only more likely to develop multimorbidity, but the onset of multimorbidity is also likely to be significantly earlier.

Keywords: multimorbidity, Canada, non-communicable disease, chronic disease

\section{Introduction}

About one in three Canadians live with at least one major chronic disease, ${ }^{1}$ and this proportion is expected to rise as the population ages and the risk factors for these diseases continue to climb. ${ }^{2-4}$ As the leading cause of death worldwide, chronic diseases were responsible for 38 million $(68 \%)$ deaths in 2012. Moreover, the World Health Organization projects that the total annual number of deaths due to chronic disease will increase to 52 million by $2030 .{ }^{5}$ In Canada, heart disease, stroke, cancer, chronic respiratory diseases and diabetes accounted for $62.7 \%$ of all deaths in 2011. ${ }^{6}$ Having two or more chronic diseases concurrently, referred to as multimorbidity, adds another layer of complexity to their prevention and management, in part because people with multiple diseases are at a greater risk of adverse health
Key findings

- In $2011 / 12,12.9 \%$ of Canadian adults aged 20 years plus had two or more chronic conditions and $3.9 \%$ had three or more.

- Arthritis, mood disorder and/or anxiety, and asthma were the most common chronic conditions and appeared prominently in multimorbidity groupings.

- The prevalence of multimorbidity increases with age, with lower household incomes and with lower education levels within the household.

- As multimorbidity becomes the norm for individuals living with chronic disease, it is all the more important to assess chronic diseases from a holistic perspective rather than from a single-disease-centric approach.

outcomes, more frequent hospitalizations and greater health care needs. ${ }^{7}$

Multimorbidity is increasingly recognized as a key public health issue. Despite that, its epidemiology is not well understood. Estimates of the prevalence of multimorbidity vary from $13.1 \%{ }^{8}$ to $90 \%{ }^{9}$, largely due to differences in case definitions, data sources and study populations. ${ }^{10}$ The most common way to measure multimorbidity is to count whether a person has two or more of a predefined list of chronic conditions. ${ }^{6}$ However, the choice of conditions can influence prevalence estimates. For example, Agborsangaya et al. ${ }^{11}$ found that $36 \%$ of Albertans had two or more chronic conditions, but their definition included obesity, which itself had a prevalence of

Author reference:

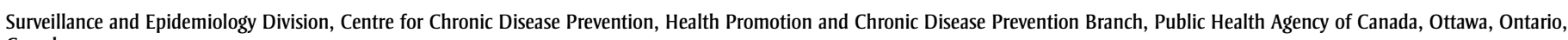
Canada

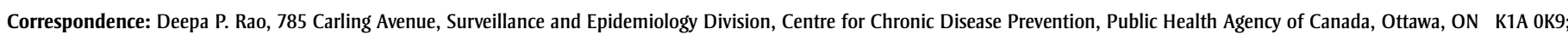
Tel: 613-946-5397; Email: deepa.rao@phac-aspc.gc.ca 
$28.1 \%$. Limiting a study sample to certain sub-populations, such as institutionalized populations or older populations, would also affect estimates. ${ }^{9,12-16}$

The main objective of this study was to examine the prevalence of multimorbidity in the adult Canadian population by selected sociodemographic variables and risk behaviours. Our secondary objectives were to examine the prevalence of disease dyads and triads.

\section{Methods}

\section{Data source}

This study is based on an analysis of the Canadian population aged 20 and older using data derived from the 2011/12 Canadian Community Health Survey (CCHS). The CCHS is a cross-sectional population health survey that includes Canadians aged 12 years and older but not those living in nursing homes or longterm care facilities or on reserves, full-time members of the Canadian Armed Forces, or civilian residents of military bases. The survey was designed to derive estimates at the national and provincial levels and for 110 health regions in Canada. Details about survey methodology are described elsewhere. ${ }^{17}$ A multi-stage sample allocation strategy ensures relatively equal weighting to the health regions and the provinces.

\section{Study variables}

To identify the prevalence of specific chronic diseases, CCHS respondents were asked about those of their long-term conditions that were "expected to last or have already lasted 6 months or more and that have been diagnosed by a health professional." Each respondent was asked about their demographic and socioeconomic characteristics including sex, age, household characteristics (i.e. number of people in the household, highest level of education, household income) and Aboriginal identity. For our analysis, we assigned a relative measure of socioeconomic status to each respondent based on their reported total household income and household characteristics, according to
Statistics Canada's household income adequacy quintiles. We used these quintiles to examine differences between the lowest income level and the highest. The Survey captures behaviours such as smoking (daily or occasional vs. not at all), dietary habits (5 or more servings of fruits and vegetables per day ${ }^{18}$ vs. less than 5), leisure-time physical activity (active or moderately active vs. inactive) and obesity (body mass index $\geq 30$ ) based on selfreported information, as well as the risk conditions of high blood pressure and stress (not at all, not very or a bit stressful vs. quite a bit or extremely stressful). ${ }^{18}$ These behavioural risk factors for chronic disease were identified through a consultative process between the Public Health Agency of Canada and relevant stakeholders. ${ }^{19}$

\section{Multimorbidity case definition}

We defined multimorbidity as having two or more $(2+)$ and three or more chronic diseases $(3+)$ from a list of nine. This definition was established by an expert working group convened by the Public Health Agency of Canada in 2012. ${ }^{20}$ The diseases were selected based on their chronic duration, high population prevalence in Canada, significant societal and/or economic impact, and amenability to primary prevention. ${ }^{20}$ Based on these criteria, and data availability in the CCHS, the nine diseases we included in this study were arthritis, mental disorder (mood disorder and/or anxiety), asthma, diabetes mellitus, heart disease, chronic obstructive pulmonary disease (COPD, only available for ages 35 years and older), cancer, stroke, and Alzheimer's disease and related dementias. We analysed data using the $2+$ and $3+$ chronic disease case definitions.

\section{Statistical analyses}

The prevalence of multimorbidity for the general population, and stratified by sex, were estimated. Common dyads and triads of diseases were identified within each of the four age groups (20-34, 35-49, 50-64, $65+$ years). ${ }^{21}$ Data are reported for the top five combinations that accounted for at least $5 \%$ of Canadians with multimorbidity within the respective pairing group (dyad or triad) and age group.
Univariate logistic models were used to examine the relationship between multimorbidity and various sociodemographic, health and behavioural risk factors, including current age, sex, household income, household education level, Aboriginal status, area of residence (urban vs. rural), physical activity, fruit and vegetable consumption, smoking status, stress level, high blood pressure and obesity. Odds ratios were used to measure associations and the Wald $\chi^{2}$ test for statistical analyses. A multivariate model using backward stepwise logistic regression analysis identified factors significantly $(p<.05)$ associated with multimorbidity (defined using the more conservative $3+$ conditions vs. 2, 1 or 0 conditions). Multivariate analyses were stratified by age to account for effect modification. Chi-square analyses were used to test for trend of physical activity across age groups.

CCHS data were weighted to be representative of the Canadian population, and $95 \%$ confidence intervals (CIs) of prevalence estimates and odds ratios (ORs) were calculated using a bootstrap resampling technique (500 replications) for all analyses to account for the complexity of survey design. Statistical analyses were performed using SAS procedure statements (SAS EG, version 5.1, SAS Institute Inc., Cary, North Carolina, US).

\section{Results}

\section{Prevalence and distribution of multimorbidity by demographics and risk factors}

In $2011 / 12,12.9 \% \quad(95 \% \quad \mathrm{CI}: 12.6-13.2$; data not shown) of Canadians aged 20 years and over $(n=105416)$ reported having two or more $(2+)$ chronic diseases and $3.9 \% \quad$ (95\% CI: 3.7-4.1; data not shown) reported having three or more $(3+)$ chronic diseases. Whatever the case definition used $(2+$ or $3+$ diseases $)$, the prevalence of multimorbidity showed similar trends across sociodemographic characteristics and risk factors (Table 1). Of those reporting $3+$ diseases, the prevalence of multimorbidity was significantly higher $(p<.05)$ in women $(4.5 \%$ vs. $3.3 \%$ for men; $O R=1.3$, $95 \%$ CI: $1.2-1.4)$, older Canadians (11.3\% of the $65+$ year age group vs. $0.4 \%$ of the 
TABLE 1

Distribution and prevalence of multimorbidity ${ }^{\mathrm{a}}$ by sociodemographic characteristics (CCHS 2011/12, population aged $\geq 20$ years)

\begin{tabular}{|c|c|c|c|c|c|c|}
\hline & $\begin{array}{c}\mathbf{N} \\
\text { (unweighted) }\end{array}$ & $\begin{array}{l}\% \text { of population } \\
\text { (weighted) }\end{array}$ & $\begin{array}{c}\text { Prevalence of } \\
2+\text { chronic } \\
\text { diseases, } \%\end{array}$ & $\begin{array}{c}\text { Prevalence of } \\
3+\text { chronic } \\
\text { diseases, } \%\end{array}$ & $\begin{array}{l}\text { Crude OR } \\
(95 \% \mathrm{Cl})^{\mathrm{b}}\end{array}$ & $\begin{array}{c}\text { Adjusted OR } \\
\qquad(95 \% \mathrm{Cl})^{\mathrm{b}}\end{array}$ \\
\hline Total & 105416 & & 12.9 & 3.9 & & \\
\hline \multicolumn{7}{|l|}{ Sex } \\
\hline Female & 58972 & 50.9 & 15.1 & 4.5 & $1.4(1.3-1.5)$ & $1.3(1.2-1.4)$ \\
\hline Male & 46444 & 49.1 & 10.6 & 3.3 & 1.0 & 1.0 \\
\hline $20-34$ & 21390 & 26.7 & 3.1 & 0.4 & 1.0 & 1.0 \\
\hline $35-49$ & 21787 & 27.2 & 6.5 & 1.6 & $4.5(3.2-6.2)$ & $4.5(3.2-6.2)$ \\
\hline $50-64$ & 31449 & 27.7 & 16.4 & 4.7 & $13.7(10.1-18.5)$ & $13.6(10.1-18.4)$ \\
\hline $65+$ & 30790 & 18.3 & 31.3 & 11.3 & $35.4(26.5-47.3)$ & $35.0(26.2-46.8)$ \\
\hline \multicolumn{7}{|l|}{ Household income quintile } \\
\hline 4 & 19559 & 20.0 & 9.6 & 2.2 & $1.5(1.2-1.9)$ & $1.4(1.1-1.7)$ \\
\hline 5 (Highest) & 21404 & 20.7 & 7.7 & 1.5 & 1.0 & 1.0 \\
\hline \multicolumn{7}{|l|}{ Highest household education } \\
\hline Less than High school & 11784 & 6.7 & 30.2 & 11.6 & $4.3(3.9-4.8)$ & $1.8(1.6-2.1)$ \\
\hline High school completed & 12970 & 10.9 & 17.1 & 5.6 & $2.0(1.7-2.3)$ & $1.5(1.3-1.7)$ \\
\hline Some post-secondary & 3575 & 4.0 & 15.6 & 5.0 & $1.7(1.4-2.2)$ & $1.6(1.3-2.1)$ \\
\hline Post-secondary completed & 70222 & 78.4 & 10.7 & 2.9 & 1.0 & 1.0 \\
\hline \multicolumn{7}{|l|}{ Aboriginal status } \\
\hline Aboriginal & 5081 & 4.4 & 17.3 & 6.6 & $1.7(1.4-2.1)$ & $2.7(2.2-3.4)$ \\
\hline Lived in Canada $\geq 5$ years & 14025 & 21.2 & 11.6 & 3.4 & $0.8(0.7-0.9)$ & $0.7(0.6-0.8)$ \\
\hline Canadian-born & 87448 & 75.7 & 13.7 & 4.2 & 1.0 & 1.0 \\
\hline \multicolumn{7}{|l|}{ Risk Factors } \\
\hline High blood pressure & 28734 & 20.6 & 30.7 & 11.6 & $6.7(6.1-7.4)$ & $3.2(2.9-3.5)$ \\
\hline Obese & 21442 & 18.8 & 20.5 & 6.9 & $2.5(2.3-2.8)$ & $2.7(2.4-3.0)$ \\
\hline Inactive & 49780 & 48.1 & 15.4 & 5.0 & $2.1(1.9-2.4)$ & $1.7(1.6-1.9)$ \\
\hline High stress & 21682 & 23.6 & 16.8 & 5.3 & $1.6(1.4-1.7)$ & $2.5(2.2-2.8)$ \\
\hline$<5$ servings of fruit and vegetables/day & 58732 & 60.2 & 12.6 & 3.6 & $1.1(1.0-1.2)$ & $1.2(1.1-1.4)$ \\
\hline Smoker & 22225 & 21.2 & 14.1 & 4.5 & $1.2(1.1-1.3)$ & $2.1(1.9-2.4)$ \\
\hline
\end{tabular}

Abbreviations: CCHS, Canadian Community Health Survey; CI, confidence interval; OR, odds ratio.

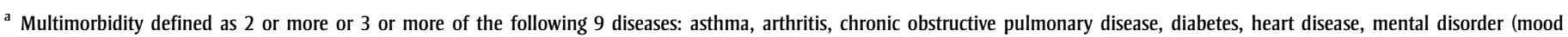
disorder and/or anxiety), Alzheimer's disease and related dementias, cancer, and stroke.

${ }^{\mathrm{b}}$ For prevalence of $3+$ chronic diseases, adjusted for age and sex.

20-34 year age group; OR $=35.0,95 \% \mathrm{CI}$ : 26.2-46.8), those living in the lowest income quintile $(7.4 \%$ vs. $1.5 \%$ of the highest income quintile; $\mathrm{OR}=3.7,95 \% \mathrm{CI}$ :
3.1-4.5), those living in households where the highest education attained was less than high school (11.6\% vs. $2.9 \%$ of households with post-secondary school education;
$\mathrm{OR}=1.8,95 \% \mathrm{CI}: 1.6-2.1)$, those selfidentifying as Aboriginal (6.6\% vs. $4.0 \%$ of non-Aboriginal populations; $\mathrm{OR}=2.7$, 95\% CI: 2.2-3.4) and those born in Canada 
( $4.2 \%$ vs. $3.4 \%$ of immigrants living in Canada for $\geq 5$ years; OR $=0.7,95 \% \mathrm{CI}$ : 0.6-0.8).

High blood pressure $(\mathrm{OR}=3.2,95 \% \mathrm{CI}$ : 2.9-3.5), obesity (OR $=2.7,95 \% \mathrm{CI}: 2.4-$ 3.0 ), inactivity (OR $=1.7,95 \% \mathrm{CI}: 1.6-$ 1.9), high stress ( $\mathrm{OR}=2.5,95 \% \mathrm{CI}$ : 2.2-2.8), fewer than five servings of fruit and vegetables per day $(\mathrm{OR}=1.2$, 95\% CI: 1.1-1.4) and smoking (OR $=2.1$, $95 \%$ CI: 1.9-2.4) were significantly associated with multimorbidity using the $3+$ diseases case definition (Table 1).

Of adults aged 20 to 65 years, $2.2 \%$ ( $95 \%$ CI: $2.1-2.4)$ reported $3+$ coexisting chronic conditions and $8.8 \%$ (95\% CI: 8.4-9.1) reported $2+$ chronic conditions (data not shown).

\section{Chronic disease prevalence and common multimorbidity combinations}

We estimated the prevalence of certain chronic diseases to identify multimorbidity for the overall population. We found that arthritis (17.6\% , 95\% CI: 17.2-17.9), mood disorder and/or anxiety $(11.2 \%, 95 \% \mathrm{CI}$ : $10.8-11.5)$, and asthma (8.1\%, $95 \%$ CI: $7.8-$ 8.4) were the three chronic conditions most commonly exhibited. We found that women had significantly higher rates of asthma $(9.4 \%$ vs. $6.7 \%)$, arthritis $(21.7 \%$ vs. $13.3 \%$ ), COPD (3.4\% vs. $2.7 \%$ ), and mood disorder and/or anxiety (14.1\% vs. $8.1 \%$ ) while men had significantly higher rates of diabetes mellitus (7.8\% vs. 6.0\%) and heart disease $(6.4 \%$ vs. $4.6 \%)$ (Table 2$)$.

The most commonly observed combinations of chronic diseases within the population varied by age group (Table 3 ). The disease dyad with highest prevalence was arthritis and mood disorder/anxiety (37.8\%, 95\% CI: 35.6-40.0) followed by arthritis and heart disease $(35.2 \%, 95 \% \mathrm{CI}$ : 33.2-37.2) and arthritis and diabetes (35.2\%, 95\% CI: 33.1-37.3). Arthritis, asthma and mood disorder/anxiety was the most commonly reported triad (15.5\%, 95\% CI: 13.8-17.1) followed by arthritis, diabetes and heart disease $(15.1 \%, 95 \% \mathrm{CI}$ : 13.6-16.7) and asthma, arthritis and COPD (14.7\%, 95\% CI: 13.2-16.2).

Mood disorder and/or anxiety accounted for 51.6\% (95\% CI: 49.2-53.9; data available on request) of reported multimorbidity in younger Canadians (aged 20-34 years). In those aged 35 years and older, the combinations of diseases begin to show more heterogeneity, with the prevalence of particular multimorbidity combinations decreasing with age. Mood disorder and/or anxiety explained less of the overall multimorbidity burden $(25.3 \%$, 95\% CI: 24.5-26.1; data available on request) within the older age group. Not surprisingly, the more common or prevalent an individual disease is within the population (see Table 2), the more likely that it contributed to rates of multimorbidity. As a consequence, diseases such as diabetes or COPD contributed more to the multimorbidity burden in the older age groups. It is worth noting that the top five multimorbidity combinations follow the same general trends across sexes, except that the fifth most common disease combination was diabetes and heart disease in men and arthritis and COPD in women (data not shown).

\section{Determinants of multimorbidity $(3+$ chronic diseases)}

After adjusting for all variables in the model, we found multimorbidity to be significantly associated with sex, age, household income, Aboriginal status, physical activity, smoking status, stress level and obesity. Stratification by age suggests that physical inactivity progressively, and significantly as of age 50 years and over, contributes to increases in the prevalence of multimorbidity (Table $4 ; p<.001$ ).

In the younger age group (20-34 years), low income quintile was the only demographic risk factor significantly associated with multimorbidity (lowest quintile adjusted OR $=4.5,95 \%$ CI: 1.3-15.7). Health conditions such as obesity (adjusted OR $=2.7,95 \% \mathrm{CI}: 1.4-5.2$ ) and high stress (adjusted OR $=2.9$, $95 \%$ CI: 1.6-5.2) were also significantly associated with multimorbidity.

In the 35- to 49-year age group, low income was once again a significant contributor to

TABLE 2

Prevalence of chronic diseases in the general population and among participants with multimorbidity ( $2+$ or $3+$ chronic diseases), (CCHS 2011/12, age $\geq 20$ years)

\begin{tabular}{|c|c|c|c|c|c|c|}
\hline \multirow[t]{2}{*}{ Chronic disease } & \multicolumn{2}{|c|}{ Overall population } & \multicolumn{2}{|c|}{ Men } & \multicolumn{2}{|c|}{ Women } \\
\hline & $\mathbf{N}$ & Prevalence, \% & $\mathbf{N}$ & Prevalence, \% & $\mathbf{N}$ & Prevalence, \% \\
\hline Arthritis & 25880 & 17.6 (17.2-17.9) & 8858 & $13.3(12.8-13.7)$ & 17022 & $21.7(21.1-22.3)$ \\
\hline Mental disorders & 12652 & $11.2(10.8-11.5)$ & 4147 & $8.1(7.6-8.5)$ & 8505 & $14.1(13.6-14.6)$ \\
\hline Asthma & 9000 & $8.1(7.8-8.4)$ & 3163 & $6.7(6.3-7.1)$ & 5837 & $9.4(9.0-9.9)$ \\
\hline Diabetes mellitus & 9450 & $6.9(6.6-7.1)$ & 4828 & $7.8(7.4-8.1)$ & 4622 & $6.0(5.7-6.4)$ \\
\hline Heart disease & 8218 & $5.5(5.3-5.7)$ & 4289 & $6.4(6.0-6.8)$ & 3929 & $4.6(4.3-4.9)$ \\
\hline COPD & 4701 & $3.1(2.9-3.2)$ & 1859 & $2.7(2.5-2.9)$ & 2842 & $3.4(3.2-3.7)$ \\
\hline Cancer & 3694 & $2.5(0.4-2.7)$ & 1476 & $2.2(2.0-2.4)$ & 2218 & $2.9(2.6-3.1)$ \\
\hline Stroke & 1944 & $1.3(1.2-1.4)$ & 925 & $1.3(1.2-1.4)$ & 1019 & $1.3(1.1-1.5)$ \\
\hline Alzheimer's and related dementias & 634 & $0.5(0.4-0.6)$ & 330 & $0.5(0.4-0.7)$ & 304 & $0.5(0.4-0.6)$ \\
\hline
\end{tabular}

Abbreviations: CCHS, Canadian Community Health Survey; COPD, chronic obstructive pulmonary disease.

Note: Mental disorders are mood disorders and/or anxiety. 
TABLE 3

Prevalence of the most common chronic disease dyads and triads, by age group (CCHS 2011/12, age $\geq 20$ years)

\begin{tabular}{|c|c|c|c|}
\hline \multicolumn{4}{|c|}{ Prevalence, \% (OR; 95\% CI) } \\
\hline Overall & Age 20-34 years & Age 35-49 years & Age 50-64 years \\
\hline \multicolumn{4}{|c|}{ Disease pairs } \\
\hline $\begin{array}{l}\text { Arthritis and mental disorder } \\
(37.8 ; 35.6-40.0)\end{array}$ & $\begin{array}{l}\text { Arthritis and mental disorder } \\
\text { (79.7; 68.0-91.4) }\end{array}$ & $\begin{array}{l}\text { Arthritis and mental disorder } \\
(53.3 ; 44.7-62.0)\end{array}$ & $\begin{array}{l}\text { Arthritis and mental disorder } \\
(46.9 ; 42.6-51.20)\end{array}$ \\
\hline $\begin{array}{l}\text { Arthritis and heart disease } \\
(35.2 ; 33.2-37.2)\end{array}$ & $\begin{array}{l}\text { Asthma and mental disorder } \\
(78.7 ; 66.3-91.0)\end{array}$ & $\begin{array}{l}\text { Asthma and mental disorder } \\
(49.4 ; 41.4-57.5)\end{array}$ & $\begin{array}{l}\text { Arthritis and asthma } \\
(40.0 ; 36.0-43.9)\end{array}$ \\
\hline $\begin{array}{l}\text { Arthritis and diabetes mellitus } \\
(35.2 ; 33.1-37.3)\end{array}$ & $\begin{array}{l}\text { Arthritis and asthma } \\
(66.2 ; 52.5-79.9)\end{array}$ & $\begin{array}{l}\text { Arthritis and asthma } \\
(45.3 ; 37.4-53.3)\end{array}$ & $\begin{array}{l}\text { Arthritis and diabetes mellitus } \\
(35.0 ; 30.8-39.2)\end{array}$ \\
\hline $\begin{array}{l}\text { Arthritis and asthma } \\
(34.0 ; 31.9-36.1)\end{array}$ & $\begin{array}{l}\text { Mental disorder and heart disease } \\
(31.4 ; 16.3-46.5)\end{array}$ & $\begin{array}{l}\text { COPD and mental disorder } \\
(32.1 ; 25.0-39.2)\end{array}$ & $\begin{array}{l}\text { Arthritis and COPD } \\
(32.6 ; 28.8-36.4)\end{array}$ \\
\hline $\begin{array}{l}\text { Arthritis and COPD } \\
(28.9 ; 27.0-30.8)\end{array}$ & $\begin{array}{l}\text { Asthma and heart disease } \\
(18.8 ; 6.8-30.7)\end{array}$ & $\begin{array}{l}\text { Diabetes mellitus and mental disorder } \\
(23.2 ; 16.9-29.4)\end{array}$ & $\begin{array}{l}\text { Arthritis and heart disease } \\
(28.4 ; 24.7-32.1)\end{array}$ \\
\hline \multicolumn{4}{|c|}{ Disease triads } \\
\hline $\begin{array}{l}\text { Asthma, arthritis and mental disorder } \\
(15.5 ; 13.8-17.1)\end{array}$ & $\begin{array}{l}\text { Arthritis, asthma and mental disorder } \\
(64.2 ; 50.3-78.2)\end{array}$ & $\begin{array}{l}\text { Arthritis, asthma and mental disorder } \\
(31.3 ; 24.2-38.4)\end{array}$ & $\begin{array}{l}\text { Arthritis, asthma and mental disorder } \\
(20.4 ; 17.0-23.8)\end{array}$ \\
\hline $\begin{array}{l}\text { Arthritis, diabetes mellitus and heart } \\
\text { disease } \\
(15.1 ; 13.6-16.7)\end{array}$ & $\begin{array}{l}\text { Asthma, heart disease and mental } \\
\text { disorder } \\
(18.2 ; 6.3-30.2)\end{array}$ & $\begin{array}{l}\text { Asthma, COPD and mental disorder } \\
(19.2 ; 13.2-25.3)\end{array}$ & $\begin{array}{l}\text { Arthritis, asthma and COPD } \\
(19.58 ; 16.19-22.96)\end{array}$ \\
\hline $\begin{array}{l}\text { Arthritis, asthma and COPD } \\
(14.7 ; 13.2-16.2)\end{array}$ & $\begin{array}{l}\text { Arthritis, heart disease and mental } \\
\text { disorder } \\
(17.6 ; 4.1-31.1)\end{array}$ & $\begin{array}{l}\text { Arthritis, COPD and mental disorder } \\
(19.0 ; 12.8-25.2)\end{array}$ & $\begin{array}{l}\text { Arthritis, COPD and mental disorder } \\
(17.2 ; 13.6-20.9)\end{array}$ \\
\hline $\begin{array}{l}\text { Arthritis, COPD and mental disorder } \\
(12.0 ; 10.4-13.5)\end{array}$ & $\begin{array}{l}\text { Diabetes mellitus, heart disease and } \\
\text { mental disorder } \\
(10.5 ; 0.0-21.6)\end{array}$ & $\begin{array}{l}\text { Arthritis, asthma and COPD } \\
(13.3 ; 8.7-17.8)\end{array}$ & $\begin{array}{l}\text { Arthritis, diabetes mellitus and mental } \\
\text { disorder } \\
(16.33 ; 12.96-19.71)\end{array}$ \\
\hline $\begin{array}{l}\text { Arthritis, diabetes mellitus and mental } \\
\text { disorder } \\
(11.9 ; 10.5-13.4)\end{array}$ & $\begin{array}{l}\text { Arthritis, diabetes mellitus and mental } \\
\text { disorder } \\
(9.5 ; 0.0-19.0)\end{array}$ & $\begin{array}{l}\text { Arthritis, diabetes mellitus and mental } \\
\text { disorder } \\
(13.2 ; 8.3-18.1)\end{array}$ & $\begin{array}{l}\text { Arthritis, diabetes mellitus and heart } \\
\text { disease } \\
(12.1 ; 9.2-15.1)\end{array}$ \\
\hline
\end{tabular}

Abbreviations: CCHS, Canadian Community Health Survey; $\mathrm{CI}$, confidence interval; OR, odds ratio; COPD, chronic obstructive pulmonary disease; OR, odds ratio.

Notes: Mental disorders are mood disorders and/or anxiety.

Only disease combinations with a prevalence of $>5 \%$ within each age group are included in the table.

Prevalence measures represent dyad and triad estimates in those with $2+$ or $3+$ chronic disease multimorbidity, respectively.

multimorbidity (lowest quintile adjusted $\mathrm{OR}=7.5,95 \% \mathrm{CI}: 4.0-13.7)$ as were obesity (adjusted OR $=2.5,95 \% \mathrm{CI}$ : 1.7-3.8); high stress (adjusted OR $=1.7$, 95\% CI: 1.2-2.4); and smoking (adjusted $\mathrm{OR}=2.6,95 \% \mathrm{CI}: 1.8-3.8)$.

Among 50- to 64-year-olds, women (adjusted OR $=1.3$, 95\% CI: 1.1-1.6), low income (lowest quintile adjusted $\mathrm{OR}=5.3$, 95\% CI: 4.4-7.9), and Aboriginal status (adjusted OR $=2.0,95 \% \mathrm{CI}$ : $1.5-2.8$ ) were significantly associated with multimorbidity (Table 4). Being inactive emerged as a significant risk factor (adjusted OR $=1.4$, $95 \%$ CI: 1.1-1.7). Smoking (adjusted $\mathrm{OR}=1.5,95 \% \mathrm{CI}: 1.2-1.8$ ), high stress (adjusted OR $=2.1,95 \% \mathrm{CI}: 1.7-2.5$ ), and obesity (adjusted OR $=2.24,95 \%$ CI: $1.8-2.7)$ remained significantly associated with multimorbidity.
In those aged 65 years and over, low income (lowest quintile adjusted OR $=2.5$, 95\% CI: 1.8-3.5) and Aboriginal status (adjusted OR $=2.4,95 \% \mathrm{CI}: 1.7-3.3$ ) were significantly associated with multimorbidity as were risk factors such as inactivity (adjusted OR $=1.7,95 \% \mathrm{CI}$ : 1.5-2.0), high stress (adjusted OR $=2.1$, 95\% CI: 1.7-2.5), and obesity (adjusted $\mathrm{OR}=1.9,95 \% \mathrm{CI}: 1.6-2.2)$.

\section{Discussion}

The analyses we present in this report align with identified calls for improvements in measuring multimorbidity to respond to program and policy needs. ${ }^{22}$ Unlike comorbidity, which has a primary condition, multimorbidity is the concurrent existence of multiple conditions without an index condition. As mentioned previously, published prevalence estimates of multimorbidity vary widely, ${ }^{10}$ likely due to differences in how multimorbidity is defined and the methodology used, including population characteristics, sample size and recruitment methods. ${ }^{10}$ Using data representative of the general adult population in Canada, our analysis suggests that, in 2011/12, the overall prevalence of multimorbidity was $12.9 \%$ (95\% CI: 12.6-13.2) in those who reported having $2+$ chronic diseases and $3.9 \%$ (95\% CI: 3.7-4.1) in those who reported having $3+$ chronic diseases.

The strong association between age and multimorbidity is well recognized, ${ }^{12-14}$ but some key findings from our study merit attention. First, although multimorbidity was higher in the older population $65+$ years), $2.2 \%$ of Canadians aged 20 to 65 
TABLE 4

Analysis of the association between selected sociodemographic characteristics, behavioural risk factors and multimorbidity ${ }^{\mathrm{a}}$ ( $3+$ chronic diseases) by age (CCHS 2011/12)

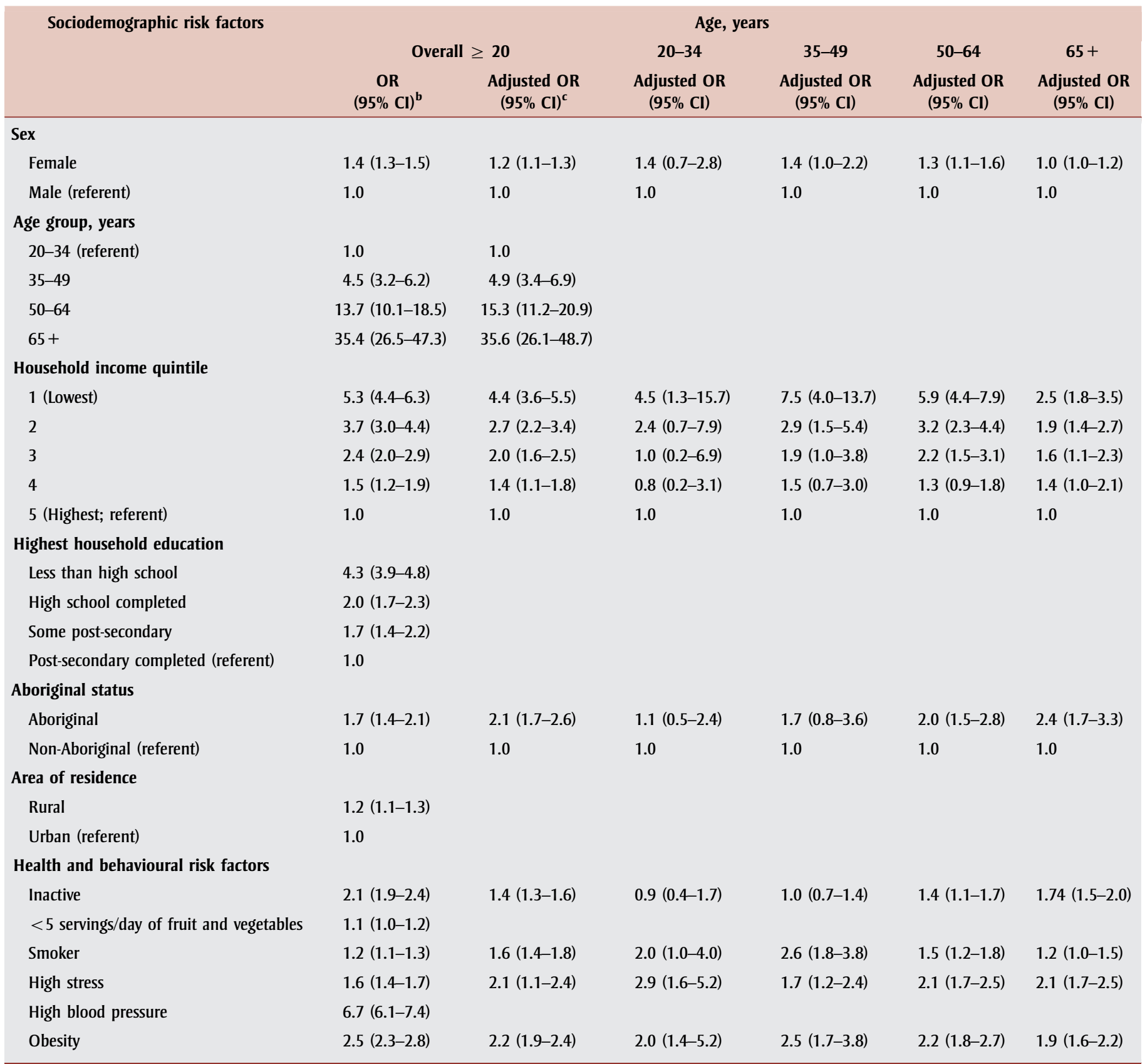

Abbreviations: CCHS, Canadian Community Health Survey; $\mathrm{Cl}$, confidence interval; COPD, chronic obstructive pulmonary disease; OR, odds ratio.

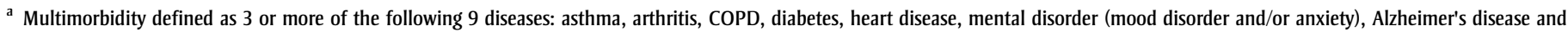
related dementias, cancer, stroke.

b Crude odds ratio.

c Odds ratio adjusted for sex, age, household education, household income quintile, Aboriginal status, activity level, smoking status, stress, high blood pressure, obesity.

years reported 3 or more coexisting chronic conditions, and $8.8 \%$ reported 2 or more coexisting chronic conditions, in keeping with previous Canadian studies. ${ }^{11}$

Second, the association of risk factors and multimorbidity increased with age.
However, demographic characteristics such as low income were also significantly associated with multimorbidity irrespective of age. In the overall population, social deprivation resulted in a 3.7 odds of multimorbidity, but when examined across age groups, the odds of multimorbidity were notably higher in middle age, with odds of 7.5 for those aged 35 to 49 years and 5.9 for those aged 50 to 64 years. This differentiation of multimorbidity prevalence in middle age based on social deprivation supports the findings of Barnett et al. ${ }^{23}$ who noted that the onset of multimorbidity occurred 
10 to 15 years earlier in people living in the lowest socioeconomic conditions. Groups living in lower socioeconomic conditions may therefore have greater clinical management needs earlier in their lives and may live with multimorbidity for longer. Whether the progressive increase in prevalence of multimorbidity with age is due to a concentration of common risk factors, such as high stress or smoking, or due to ecological reasons, such as unemployment and gender inequality, is beyond the scope of our analyses. However, it warrants further investigation, particularly as unemployment, income inequality, physical activity level and stress are preventable risk factors that benefit from multisectoral action.

Third, we noticed patterns in the prevalence of chronic diseases. Arthritis, mood disorder and/or anxiety and asthma, which were the most common chronic conditions overall, were prominent in disease groupings, and were each more significantly prevalent in women. Anxiety and/or mood disorders accounted for over half of reported multimorbidity in younger Canadians (20-34 years). In addition, younger women had higher rates of mental disorders than their male counterparts.

Finally, our finding that arthritis and mental disorder are the most common pairing of multimorbidity supports the findings from a 2012 Canadian study that identified arthritis as a top condition in multimorbidity dyads. ${ }^{24}$ Our analysis into common disease dyads and triads underscores the need to further investigate clusters of diseases to inform programs focused on integrated and holistic care. ${ }^{25}$

\section{Strengths and limitations}

Although the prevalence of multimorbidity and associated determinants we found are generalizable to the non-institutionalized Canadian population, our study has its limitations. Our results are likely to be subject to recall bias since the data are based on self-reports of clinical diagnosis. The results may also be explained, in part, by the operational case definition used for multimorbidity, namely, the number and type of chronic diseases considered. Fortin et al. ${ }^{10}$ suggested that the more diseases considered, the higher the prevalence estimates. Rapoport et al. ${ }^{26}$ looked at 22 diseases and reported a higher prevalence of multimorbidity in Canada than did Cazale et al., ${ }^{27}$ who considered only 7 diseases. However, Fortin et al. ${ }^{10}$ also noted a threshold effect, with prevalence not further affected when 15 or more diseases were considered. We considered 9 chronic diseases, based on a set of public health criteria and limited to those captured via the CCHS. Finally, given the exploratory nature of our analyses and the multiple comparisons, a type 1 error is likely.

Despite these limitations, our results contributed to understanding the epidemiology of multimorbidity to inform prevention efforts, reduce disease burden and align health care services with holistic patient needs. Traditional, single disease-centric approaches may be increasingly inappropriate given that multimorbidity is becoming the norm for people living with chronic conditions. Rather, an integrated approach that addresses multiple diseases and upstream factors, such as socioeconomic determinants and behavioural risk factors, could have a broad-reaching, systematic effect on a range of outcomes including quality of life, health care costs and mortality. ${ }^{16,28}$ Further studies to understand the societal and economic impact of multimorbidity are warranted, although any findings in this area will certainly underline the need for prevention, particularly in tackling the common risk factors and determinants of common chronic diseases.

\section{References}

1. Ronksley PE, Sanmartin C, Campbell DJ, et al. Perceived barriers to primary care among western Canadians with chronic conditions. Health Rep. 2014;25:3-10.

2. Ford ES, Croft JB, Posner SF, Goodman RA, Giles WH. Co-occurrence of leading lifestyle-related chronic conditions among adults in the United States 2002-2009. Prev Chronic Dis. 2013;10:E60.

3. World Health Organization. Preventing chronic diseases: a vital investment: WHO global report. Geneva $(\mathrm{CH})$ : World Health Organization; 2005.

4. Starfield B. Challenges to primary care from co- and multi-morbidity Prim Health Care Res Dev. 2011;12(1):1-2.
5. Health statistics and information systems: projections of mortality and causes of death, 2015 and 2030 [Internet]. Geneva (CH): World Health Organization; 2015 (cited 2015 Jan 16). Available from: http://www.who.int/heal thinfo/global_burden_disease/projections/en/

6. Statistics Canada. Age-standardized mortality rates by selected causes, by sex (both sexes) [Internet]. Ottawa (ON): Statistics Canada; [updated 2014 Jan 28, cited 2014 Dec 1]. Available from: http://www.statcan.gc.ca/ tables-tableaux/sum-som/101/cst01/health30 a-eng.htm

7. Boyd CM, Fortin M. Future of multimorbidity research: how should understanding of multimorbidity inform health system design? Public Health Rev. 2010;32(2):451-74.

8. Menotti A, Mulder I, Nissinen A, Giampaoli S, Feskens EJ, Kromhout D. Prevalence of morbidity and multimorbidity in elderly male populations and their impact on 10-year all-cause mortality: the FINE study (Finland, Italy, Netherlands, Elderly). J Clin Epidemiol. 2001;54(7):680-6.

9. Fortin M, Bravo G, G, Hudon C, Vanasse A, Lapointe L. Prevalence of multimorbidity among adults seen in family practice. Ann Fam Med. 2005;3(3):223-8.

10. Fortin M, Stewart M, Poitras ME, Almirall MD, Maddocks H. A systematic review of prevalence studies on multimorbidity: toward a more uniform methodology. Ann Fam Med. 2012;10(2):142-51.

11. Agborsangaya $\mathrm{CB}$, Ngwakongnwi E, Lahtinen $\mathrm{M}$, Cooke T, Johnson JA. Multimorbidity prevalence in the general population: the role of obesity in chronic disease clustering. BMC Public Health. 2013;13:1161.

12. Akner G. Analysis of multimorbidity in individual elderly nursing home residents. Development of a multimorbidity matrix. Arch Gerontol Geriatr. 2009;49(3):413-9.

13. Marengoni A, Rizzuto D, Wang HX, Winblad B, Fratiglioni L. Patterns of chronic multimorbidity in the elderly population. $\mathrm{J}$ Am Geriatr Soc. 2009;57(2):225-30.

14. Schafer I, von Leitner EC, Schön G, et al. Multimorbidity patterns in the elderly: a new approach of disease clustering identifies complex interrelations between chronic conditions. PLoS One. 2010;5(12):e15941. 
15. Violán C, Foguet-Boreu Q, Roso-Llorach A, et al. Burden of multimorbidity, socioeconomic status and use of health services across stages of life in urban areas: a crosssectional study. BMC Public Health. 2014;14:530.

16. Salisbury C, Johnson L, Purdy S, Valderas JM, Montgomery AA. Epidemiology and impact of multimorbidity in primary care: a retrospective cohort study. Br J Gen Pract. 2011;61:e12-21.

17. Béland Y. Canadian Community Health Survey-methodological overview. Health Rep. 2002;13(3):9-14.

18. Statistics Canada. Canadian Community Health Survey (CCHS) data user guide: cycle 2 [Internet]. Ottawa (ON): Statistics Canada; 2012 Nov [cited 2015 May 8]. Available from: http://www23.statcan.gc. ca/imdb-bmdi/document/5071_D2_T1_V2eng.htm

19. Betancourt MT, Roberts KC, Bennett TL, Driscoll ER, Jayaraman G, Pelletier L. Monitoring chronic diseases in Canada: the Chronic Disease Indicator Framework. Chronic Dis Inj Canada. 2014;34 Supp 1:1-30.

20. Multimorbidity Technical Working Group. (Summary Report) Technical Meeting: Measurement of Multimorbidity for Chronic Disease Surveillance in Canada.Chronic Disease Surveillance and Monitoring Division, Centre for Chronic Disease Prevention Public Health Agency of Canada; 2012 [unpublished report].

21. Ward BW, Schiller JS. Prevalence of multiple chronic conditions among US adults: estimates from the National Health Interview Survey, 2010. Prev Chronic Dis. 2013;10:E65.

22. Parekh AK, Goodman RA, Gordon C, Koh HK. Managing multiple chronic conditions: a strategic framework for improving health outcomes and quality of life. Public Health Rep. 2011;126(4):460-71.

23. Barnett K, Mercer SW, Norbury M, Watt G, Wyke S, Guthrie B. Epidemiology of multimorbidity and implications for health care, research, and medical education: a cross-sectional study. Lancet. 2012;380(9836):37-43.

24. Agborsangaya CB, Lau D, Lahtinen $M$, Cooke T, Johnson JA. Multimorbidity prevalence and patterns across socioeconomic determinants: a cross-sectional survey. BMC Public Health. 2012;12:201.
25. Kronick RG, Bella M, Gilmer TP, Somers SA. The faces of Medicaid II: recognizing the care needs of people with multiple chronic conditions. Hamilton (NJ): Center for Health Care Strategies, Inc.; 2007.

26. Rapoport J, Jacobs P, Bell NR, Klarenbach S. Refining the measurement of the economic burden of chronic diseases in Canada Chronic Dis Can. 2004;25(1):13-21.

27. Cazale L, Dumitru V. Les maladies chroniques au Québec: quelques faits marquants. Zoom Santé. 2008;29:1-4.

28. Goodman RA, Posner SF, Huang ES, Parekh AK, Koh HK. Defining and measuring chronic conditions: imperatives for research, policy, program and practice. Prev Chronic Dis. 2013;10:E66. 